2. The reaction is due to the presence of bile acids and not to any other constituent of the bile.

3. One part of glycocholic or taurcholic acid in 120 ,000 parts of water lowers the surface tension of the water and sulphur will sink to the bottom.

4. No other substance in the body except soap has the same action as bile acids.

Since the original papers in the French journal referred to above are not accessible to me, I am obliged to draw on the editorial in The JournaL of the American Medical Association (March 23, 1901, p. 820) for information relative to their investigation.

1. Acetic acid, alcohol, ether, chloroform, essence of turpentine, benzoin and its derivatives, phenol and its derivatives and analin also cause the sulphur to precipitate.

2. All fluids with a surface tension greater than fifty dynes per centimeter do not allow sulphur to fall, and in all fluids with a tension less than fifty dynes the sulphur rapidly settles.

3. Lycopodium bears the same relation to fluids with a tension of thirty dynes as flowers of sulphur to fluids with a tension of fifty dynes.

In my own experiments I have noted the following:

1. The specific gravity of the fluid has no influence on the accuracy of the test.

2. The reaction of the fluid has no effect on the test.

3. In order to obtain correct results, the fluid must be clear. Cloudy or turbid urine must be filtered.

4. The urine must be free from bubbles.

5. Urine examined immediately after it is voided gives invariably the reaction for bile. This was a source of great annoyance to me until I found out that heat reduces surface tension. The urine must, therefore, be cooled off before the test is made.

6. In several cases where the reaction for bile pigment by Gmelin's test could not be obtained, the presence of bile acids could be demonstrated by the sulphur test.

7. In a case of syphilis of the liver, the urine gave the reaction for bile acids.

8 . The urine of several patients in advanced stage of tuberculosis, with swelling of the lower extremities, gave the reaction for bile acids.

9 . The stomach contents of a patient which I removed on two consecutive mornings, and which consisted almost entirely of bile, did not give the sulphur reaction.

10. Urine of three cases of pregnancy in their sixth, eighth and ninth months, respectively, gave the bile acid reaction.

11. After having experimented with more than one hundred and fifty different powders, I have found that boracic acid. iodoform, acetanilid, salol, calomel, salicylate of bismuth and salicylic acid possess this properly as does sulphur, only in a feebler degree.

I shall not theorize as to the probable effect bile acids have on digestion by virtue of their ability to lower surface tension. I have not reached yet the point in my experimentation that will warrant the making of any positive assertion. I wish merely to call your attention to a new test for bile acids, the simplicity, accuracy and sensitiveness of which should gain for it universal application, and induce others to further investigation.

resultant force tending toward the interior. Surface tension is based on. the law of capillarity, and those who wish to study the subject should consult the exhaustive bibliography and synoptical study, "References to Capillarity to the End of John Uri Lloyd and Sigmund Waldbott, Bulletin of the Lloyd Library, Pharmacy Serles No. 1, 1902.

\section{Glinical Report.}

\section{A CASE OF VICARIOUS MENSTRUATION FROM THE LOWER LIDS. \\ J. HERBERT CLAIBORNE, M.D. NEW YORK CITY.}

A young Jewish girl of 16 presented herself at the Vanderbiit Clinic on account of hemorrhagic spots under each eye. She was pale, flabby and badly nourished. In other respects she was well. She had menstruated for the first time at 13 years of agre. Since the establishment of her menses she noticed every month, two or three days before her period, that a red spot would appear under each eye. The skin would become red, the blood would rise to the surface and finally ooze through and form a clot, which dried, resulting in a crust. This lasted during her period and disappeared gradually, so that in two or three days afterward the skin would be normal again. She also said the spots would occasionally appear two or three days after her menses and would disappear as usual.

There was a hypermetropia of a mild degree with normal vision. The interior of the eyes and the lids were normal and

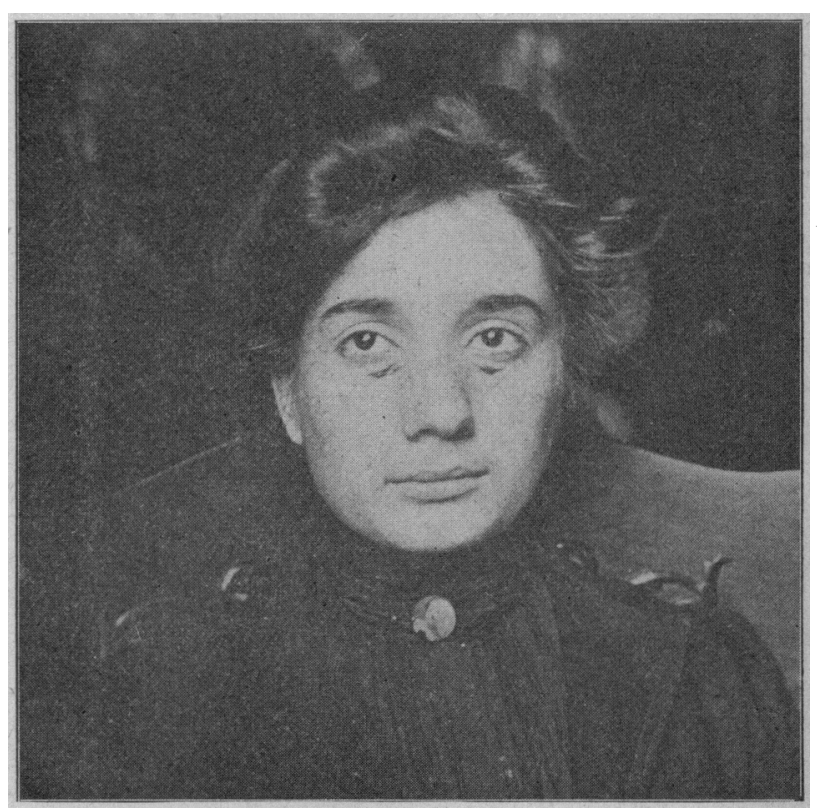

she did not complain of any visual disturbance. There was atrophic rhinitis with deflected septum. Dr. E. B. Coburn ex amined her blood and found the blood count very near to the normal, although there was a diminished quantity of hemoglobin.

The bichlorid of mercury with the compound tincture of gentian was given in this case. Her general health was much improved in consequence without the above mentioned phenomena being in any way influenced. The accompanying photograph illustrates the condition. As a rule the spots are semilunar in shape, about three-quarters of an inch below the level of the inner canthus and one-third as long as the lower lid. Dr. Geo. B. McAuliffe has referred to a case similar to this in a review on ophthalmology, published in The Critic, but without detajls. On request Dr. McAuliffe was unable to give me reference to the publication in which the case was described. I have been unable to find any other similar case on record.

39 West 36 th Street.

Epidemic Infantile Paralysis.-Something not yet under stood by medical science is the occasional development of an epidemic of infantile paralysis. Such an instance lately happened in Gloucester, Mass., thirty-eight cases being noted within a radius of four miles.Clinical Review. 